in her short journey up country with Mr. Bock, she, being an intelligent child, picked up a few words of Laos; the joints of her arms and fingers possess, it is true, according to European ideas great flexibility, but really they have it to no greater degree than those of ordinary Siamese ; it is also true that she is able to use her toes, grasping things between the big toe and the next one in a way that is surprising and amusing to Europeans, but this is a faculty which all Siame:e, being a barefooted people, possess to a greater or less degree; the child was lo kked upon here as even a greater natural curiosity than she is considered to be in. England, her parents being in the habit of taking her about and showing her for a small reward, and the price they obtained for her (in native currency equal to 60 .) being twice that of an ordinary child of the same age. A strange mistake has been made about the child's name, "Krao " being merely the Siamese name for whiskers, a very natural nickname for the clild to obtain. As far as I can ascertain from those who knew the child well, she is endowed with the average intelligence of Siamese children of her age and class, and beyond her abnormal hairiness presents no peculiarity.

To sum up, "she is," as you rightly remarked, " merely a lusus natura, or a sport, possessed rather of a pathological than an anthropological interest. I may add that I have carefully verified all the foregoing statements.

Bangkok, Siam, March 3

[From information that has si ice reached me I am able fully to confirm the particulars here supplied by "A Resident."A. H. K.]

\section{Singing, Speaking, and Stammering}

IN NATURE, vol. xxvii. p. 532, in the report of Dr. Stone's lecture on "Singing, Speaking, and Stammering," there appears a Classification of Vowels, which is described as an abstract of Mr. Melville Bell's scheme. I shou'd like, however, to point out that the system which $\mathrm{Mr}$. Bell has advocated for the last fifteen years is hardly re,resented in the Classification referred to. On turning to p. 63 of Mr. Bell's "Souads and their Relations," which is a new exposition of "Visible Speech," it will be seen that the vowels $I r$ and $A h$ are not described as labio-lingual, and that the threefoll 1 arrangement of the vowels as lingual, labio-lingual, and labial is abandoned as incorrect. The lecturer does not appear to have mentioned the phonetic researches of Mr. A. J. Ellis and Mr. Henry Sweet. In many important points, however, they supplement the system of Mr. Bell, and their works cannot be overlooked in the scientific study either of etymology or pronunciation. The student of language can hardly do better than begin with Mr. Ellis's "Speech in Song," and Mr. Sweet's "Handbook of Phonetics."

5. Alexandra Road, Wimbledon, S.W., April Io JAMES LECKY

THE classification of vowels to which Mr. Lecky refers is taken fro.n Mr. Melville Bell's "Principles of Elocution," which I obtained with much difficulty from a publisher in Salem, Mas:achusetts. It is dated 1878 , and may, I suppose, be held to represent the author's system at that date. I am well acquainted with the other works named by Mr. Lecky. W. H. S'TONE

As an illustrative instance of the peculiarities akin to stammering, referred to in Mr. Stone's lecture in last week's NATURE (p. 559), I may mention the case of an old Scotch lady whom I knew some years ago, and who was in the habit of interpolating at frequent intervals in her talk the wholly irrelevant words "This that here there ye ken." She herself evidently made $\mathrm{u} e$ of the words with perfect unconscionsness of their irrelevancy; indeed I doubt whether, if challenged, she would have admitted using them at all.

K.

\section{A Curious Case of Ignition}

"A curious case of iznition," quoted in Nature, vol. xxvii. p. 509, reminds me of a similar circuinstance that came under my own observati n when serving in H.M. despatch vessel Psyche, 1862-66. We were moored "head and stern" in Port Napoleon, Marseilles, on a bright summer day. A strong smell of burning was traced to the saloon skylight. On bursting open the door of the saloon it was found that a scuttle glass (a planoconvex lens) through which the solar rays were admitted and focused on a rep curtain (which was smouldering) had been substituted for a broken one, but through an oversight had not been ground on the plane surface (as is usual). The case was reported by letter, and an order issued to insure all scuttle glasses used in men-of-war for the purpose being ground.

BER'TRAM GWYNNE

\section{Fibreballs}

I HAVE seen balls of vegetable fibre, such as those referred to by Mr. G. H. Darwin in his letter of March 23 (NATURE, vol. xxvii. p. 507), in great abundance on the sea-beach at Cannes; there however they are not spherical like those de scribed by Sir A. Musgrave, but cylindrical, two or three inches in lengtb, finely and closely matted, and all wonderfully similar in appearance. In one place they had been collected and employed, if I remember rightly, to form a kind of wall. Some balls of a similar kind, but more nearly spherical and much coarser in texture, were found, on draining a pond, by Dr. Fitton, and sent by him to Sir J. Herschel, these were three or four inches across, and looked almost llke small hedge hogs rolled up.

J. H.

\section{Benevolence in Animals}

Mr. Geo. J. Romanes, in a lecture delivered in Manchester, March 12, 1879, on "Animal Inteligence," points out the following emotions which resemble human intelligence as occurring in animals below the human species, namely : fear, affection, passionateness, pugnacity, jealousy, sympathy, pride, reverence, emulation, shame, hate, curiosity, revenge, cruelty, emotion of the ludicrous, and emotion of the beautiful, and gives some remarkable instances in support of his statement. To this I can add benevolence on the part of our household cat, who was ob served to take out some fish bones frcm the house to the garden, and, being followed, was seen to have placed them in front of a miserably thin and evidently hungry stranger cat, who was devouring them; not satisfied with that, our cat returned, pro cured a fresh supply, and repeated its charitable offer, which was apparently as gratefully accepted. This act of benevolence over, our cat returned to its customary dining-place, the scullery, and ate its own dinner off the remainder of the bones, no doubt witb additional zest.

Woodend, Fortis Green, N., April 12

\section{The Zodiacal Light (?)}

LAST Friday evening about 7 p.m. my attention was called to a peculiar appearance in the western sky. The sun had set not long before. No clouds were visible but one long thin streak, and there were the usual mists near the horizon. Abjve where the sun might be, a pillar of light faintly red in colour, with soft edges, but fairly well define $d$, rose vertically from near the horizon to the height of perhaps a few degrees. It did not look like an illuminated cloud nor like rays of light shot up through a cloud, nor like anything local ; in fact I am told that it moved north. wards with the sun. Was this the zodiacal light, or merely some sunset effect? It began to grow dim about 7.10 p.m, but was visible later than this. $J$. W. B.

New Kingswood School, Lansdown, Bath, April to

\section{Braces or Waistband?}

THE writer has for the last thirty years dispensed with the use of either braces or a belt, having had his waistcoats made with short elastic straps attached inside and with holes to button on to the trousers like braces, one on each side and a third in front.

They answer as well as braces in conjunction with the ordinary waistband and buckle of the trou ers, and the wearer is saved the feeling of strain across the shoulders or round the waist con. nected with the use of braces or a belt. April 13

\section{THE TEACHING OF ELEMENTARY $M E C H A N I C S^{1}$}

$A^{T}$ the recent Annual Meeting of the Association for the Improvement of Geometrical Teaching held, as has already been noted in our columns, at University I Association for the Improvement of Geometrical Teaching, Nint General Report, January, $188_{3}$. 
College, on January 17, the following statements of work done by the Committees were presented. In Solid Geometry no progress had been made in consequence of the serious illness of the secretary (Mr. Merrifield), but the President in his subsequent address remarked that it was hoped that the Committee would meet at an early date and work out, upon the basis of what Mr. Merrifield had done, a syllabus of propositions corresponding to the IIth and I2th Books of Euclid and the simpler geometry of the sphere. In Higher Plane Geometry the Committee had revised about half of the syllabus issued in 1879 and nad added chapters on the geometry of the triangle and on geonetrical maxima and minima (copies were distributed amongst the members present, and have been subsequently circulated). In Geometrical Conics the former syllabus had also been revised and continued to the end of the hyperbola (this syllabus is also in the hands of members). In Elementary Plane Geometry the proofs of Book 1. of the Syllabus had been revised, the proofs of Book I1. drawn up, and a collection of Exercises on Books I. and II. had been added (the motion in connection with the adoption of these proofs, which was down in the President's name, had to be postponed in consequence of copies not having been circulated before the meeting). ${ }^{1}$ Gratifying testimony to the success of the Association's efforts was afforded by the fact recorded in the Council's Report that the copies of the syllabus were all disposed of, and that it was in contemplation to bring out at once a revised edition of the work in accordan ze with the changes made in the books of proofs.

In addition to the usial routine busines: the President closed the morning sitting with some remarks on the texching of arithmetic. This is a subject the claims of which upon teachers he has at many previous meetings pressed upon his hearers, it being his desire that the teaching should be put upon a sounder footing than it at present in most cases occupies. A true disciple of his old master, De Morgan, he insisted strongly upon the more frequent appeal to reason than to rule. "It seemed to him to be the wrong order to give first the rule and then the reason. Teachers should take particular examples, and work them out with ressons for every step. They should lead up to a rule by a series of examples worked out from common sense, and only when these have been thoroughly grasped should the rule be introduced as a convenient embodiment and summing up of the results attained by the application of reason and common sense." A common habit with boys is to ask, "How am I to do this?" "In his own practice he never answered that question, but he said, "What does it mean? If you will only find out what it means, then you will know how to do it." Another principle he advocated was "that all arithmetical prozesses should follow the order of thought, according to which numbers are grouped in language. .... The order of thought in the expression of numbers was from the higher group to the lower, hundreds to tens, tens to units, \&c." In this connection he referr ed to a lecture by the late $\mathrm{Mr}$. Bidder. A reform on the principles he the President) advocated would, he believed, be very valuable in teaching and in the practical operations of aithmetic. In the natural sciences arithmetic is applied to cases where approximate data only are employed. "Hence it was becoming more and more important that methols of approximation should be carefully and distinctly taught." This led him to enter a protest against the practice, frequent amongst University examiners, of setting in papers for schoolboys, "among the questions on decimal fractions, some examples to be done only by reducing recurring decimals to vulgar fractions, and then working out the result by vulgar fractions. To give prominence to such examples was simply to destroy the notion which a

${ }^{I}$ A special meeting for the purpose of considering the postponed motion was held at University College on the evening of March 20, at which the "proofs" were adopted and their publication sanctioned. good teacher would have been endeavouring to instil into a boy's mind, that decimal fractions are useful only in general for approximate results. He did not wish to say anything against recurring decimals rightly used and in their proper place." A final point was that he would substitute Horner's process for the extraction of any roots for "the awkward and almost useless special processes usually given for extracting square and cube roots. This he would teach simply as a process; but of course with fair warning to the boy by telling him that he was for once giving him a process which would lead to the desired result, an 1 that it would be a reward of his future mathematical attainments if he could get to the reason of it."

The novel feature, however, in this year's proceedings was the holding of an afternoon sitting, which was wholly devoted to the consideration of the subject of elementary mechanics. This meeting was the outcome of the recent extension of the Association's sphere of action, and proved to demonstration that the said extension had met with the approval of many of our most able physicists. The papers rcad were three in number: (I) The Teaching of Elementary Mechanics, by Mr. W. H. Besant, F.R.S. ; (2) Notes on the Teaching of Eltmentary Dynamics, by Prof. G. M. Minchin; (3) The Basis of Statics, by Prof. $\mathrm{H}$. Lamb of the University of Adelaide. (I) is remarkable as proceeding from a successful Cambridge "coach," who finds it difficult to emancipate himself "from the ideas and prejudices which are the natural results of an adherence for many years to a special set of books and to a special system of teaching. The fact constantly before $u_{s}$ in Cambridge, that mechanics are being studied with a view to success in examinations, tends to make us forget the importance of the practical application to daily life of a knowledge of mechanics, and the temptation is to luxuriate in the flowery and ornamental problens which sometimes form the staple of examination questions," whereas "millions of people must acquire a knowledge of the laws of mechanics, practical or theoretical, or both, who are not going to be tested by a Cambridge examination." It however goes without saying that at present Cambridge methods do exercise a very large influence on the teaching of mechanics throughout the country. In the case of young students and beginners, Mr. Besant considers that the first requisite for a class-room is a set of models and a quantity of machinery (segnius irritant animos, \&c.). "The bandling of systems of pulleys, and experiments with levers and screws, will guide the student, almost unconsciously, to the ideas of the transmission of motions, and of the transmission and multiplication of force. ... Then, again, experiments with falling bodies, and with an Attwood's machine, will illustrate the ideas of uniform motion and of accelerated motion, and generally of the action of gravity. . . For many students this kind of experimental teaching will probably be sufficient for the work of their lives, and it will be certainly educationally useful." The Cambridge practice has been to treat the subjects of statics and dynamics separately, and to take statics first; and the teaching is so limited that the ordinary Bachelor of Arts, whose reading has been limited to statics alone, "is sent out into the world without any perception of the laws of motion, and without any knowledge of the elementary deductions from those laws, which are necessary requisites for a true appreciation of a vast range of natural phenomena." Passing next in review the change of nomenclature and of treatment inaugurated by Professors Thomson and Tait, and the late Prof. Clerk Maxwell, Mr. Besant records his opinion that Duchayla's proof is "forced and unnatural," and causes a considerable waste of time. His wish is that the examiners should have greater freedom of action. He would, following the lead of the abovenamed eminent physicists, commence with a study of the 
elementary parts of kinematics, to include "the ideas and measures of velocity and acceleration, the parallelogram of relocities, and the parallelogram of accelerations, the motion of a point with a constant acceleration, and the acceleration of a point moving uniformly in a circle." Then would come "falling bodies and projectiles." From these particular cases the student will get a general idea of the action of force, and so be prepared for a study of the laws of motion, and of the deductions from these laws. "One of the first of these is the parallelogram of forces, and I am convinced by actual experiment of the ease with wh ch that mode of proof is appreciated by a beginner. The perception of the physical independence of forces which is really the qualitative part of the second law of motion, is not a serious difficulty to the majority of beginners in mechanics, and from this principle, with the aid of the parallelogram of velocities, the parallelogram of forces is developed easily and naturally." Next may be taken the mechanical powers and simple cases of equilibrium of bodies and systems of rods, a statement of the laws of friction, and the determination of the centres of gravity of bodies and systems. Mr. Besant also laid great stress upon graphical modes of solution, referring to $\mathrm{Mr}$. Minchin's work on Statics for numerous examples in these methods. "The discussion of the theory of moments of forces would naturally lead up to the idea of a couple and to the transformation and composition of couples." The pupil might then proceed to the impact of balls on each other: "The easiest method for every one... is to assume the invariability of momentum, and the constancy of the ratio of the relative velocities before and after impact. The consideration of the action of the forces of compression and of restitution is a more difficult idea, and should be deferred to a later stage of the student's progress. In the discussion of these points the idea of work and of kinetic and potential energy may be introduced and illustrated, gradually leading up to the statement of the general principle of energy." Dwelling upon the wonderful results that accompany the employment of this general principle, "the very concentrated essence of science," which in elementary mechanics "widens the path and shortens the road, and reduces to simple forms of thought many problems which used to be reckoned as belonging to advanced regions of the higher mechanics, and as depending for their solution on the complicated machinery of analytical process," the paper alluded to the fact that it was only as recently as 1877 that this principle of energy appeared in Part I. of the Tripos Examination - a result mainly to be attributed, we believe, to Prof. Clerk Maxwell's advocacy of it. The principle is carefully laid down and discussed in "On Matter and Motion," as well as elaborately discussed in Thomson and Tait's "Natural Philosophy," and in many recent elementary treatises. With such views of its importance, we are not surprised to find $\mathrm{Mr}$. Besant pleading for the introduction of the idea of energy as early as possible, and that every effort should be made to "illustrate the idea by means of simple cases and so to lead the student upwards, by gradual steps, to the conception of the most important principle which lies at the root of all modern science." Another point on which the paper touches is that "ill-chosen technical terms are likely to propagate erroneous ideas and confusion of thought," and reference is made to recent remarks on the use of the word "force." Then coming to the question of a syllabus of mechanics, Mr. Besant remarks that "it will be a matter of supreme importance to discuss the definitions and axioms of the subject," and instances a common definition of the word "vertical"-tbat it is the line in which a stone moves when let fall. The paper closes with a few general remarks on the value of some branches of scientific study as an education, from which we select the two following extracts:-"The safest and wisest plan seems to be to let every man, who wishes to make research in physics, find out for himself the kinds of tools which he wants, and then learn as much of the use of those tools as may be necessary." "The elementary subjects, such as mechanics and astronomy, are of more educational value to the majority of students than the higher regions of science, and only a select few should be encouraged to spend much of their time in such advanced forms of study."

(2) In this dynamics includes both statics and kinetics. The writer is in favour of continuing the old way of taking statics first, and of then proceeding to kinetics, and argues strongly against the taking the former as a particular case of the latter. Two important advantages, however, of the recent mode of treatment are not ignored, viz. that the student by concentrating his attention on force solely as change of motion, it at once proves for him the fundamental proposition of dynamics, viz. that of the "parallelogram of torces," as an immediate result of the easily admitted parallelogram of velocities ("if for the beginner the choice liy between such proofs as Duchayla's, and none, I should say, 'Assume the proposition" "); and next that "the kinetical method has the very great practical advantage that it makes the student familiar at the outset with, the idea of absolute measures of force, momentum, energy, \&c., such as are used in the C.G.S. system." The notion of acceleration is an exceedingly difficult one for beginners, and such a one, as a matter of fact, "is confined to the consideration of acceleration of constant magnitude, and, except in the case of uniform motion in a circle, to the case of acceleration in a constant direction. Thus he gets plenty of exercise in the motion of particles down inclined planes, ... but what idea does our beginner obtain of the acceleration of the motion of a particle revolving uniformly in a circle? Is there not something primâ facie very difficult, if not absurd, to him in the statement that any motion which takes place with uniform velocity can be accompanied by acceleration?" After a few more remarks to the same end, Prof. Minchin says, "So far as my own work in teaching is concerned, I bave not a moment's besitation in saying that the treatment first of kinetics and then of statics as a particular case is to be rejected. So difficult for the mere beginner are the conceptions involved in Newton's second axiom, that three months' work in combating difficulties and removing false impressions would, almost to a certainty, produce a merely negligible amount of positive knowledge." Starting from the kinetical definition of force, and thereby establishing the fundamental proposition " this does not logically compel us to continue to treat of motion, deducing rest as a particular case "), the writer, after protesting against the too great importance attached to the getting-up of "book-work," 1 expresses the opinion that the student realises the subject only by incessant application of the principles to particular cases. For this purpose nothing, he believes, is so good as numerical examples: and this in contrast to examples dealing with magnitudes as algebraical symbols, and to geometrical examples. "So long as forces are $X, Y, Z$, and moments are $L, M$, $N$, and no particular consideration of the units of different quantities is required, they are comfortable enough, but when we have to deal with pounds and foot-pounds, dynes and ergs, the utter unavailability and inutility of their knowledge are made manifest." Another point strongly insisted upon is the invariable accompaniment of figures constructed accurately to scale with all the examples. The result should be arrived at by calculations made by means of logarithmic and trigonometrical tables, and also by graphic construction by the aid of the instruments, and on all there should be, when possible, "the perpetual

I "I have met students who could write out paragraph after paragraph of general propositions in statics, and who at the same time (although such might appear to a priori reasoners impossible) could not make the faintest attempt to discuss any particular question involving the application of the principles of statics." 
exercise of a common-sense check." Too much weight may be attached to graphic statics, "but real utility is gained by making graphic methods a companion to (though not wholly a substitute for) analysis," and Prof. Minchin would assign a more conspicuous place to them in the textbooks than they at present occupy. "Their essential merit consists in their furnishing visibly to the student the whole history of a magnitude throughout a series of variations in its circumstances." Prof. Minchin would also banish such "crude" terms as "power," "weight," in the equilibrium of machines: such forces might be called "efforts" and "resistances." Passing over one or two other subjects, we come to remarks on "illogical methods of teaching"; by such a method is here meant $a$ process which introduces considerations that are not essentially necessary for the purpose aimed at-considerations that can be seen a priori to be irrelevant. The moral is pointed by the discussion of a question of usual occurrence in the text-books. The student should be able to be critic of his data, and "he ought to be taught to recognise clearly the object finally aimed at in any problem, and also to see what he must be given, and what he need not be given, in order to arrive at it." For this purpose Prof. Minchin purposely uses with his students some books which, both in their data and in their methods, are full of illogicisms. The finale comes in pointing out the desirability of making the student carefully distinguish between the weight of a body and its mass, and here he "comes down," if we mistake not, on an episcopal writer of works on dynamics, for a "remarkable misuse of language."

(3) Prof. Lamb's object is to suggest a new basis for the science of statics, and in the course of his paper he attacks certain principles and artifices, as "the transmissibility of force," and (in hydrostatics) the solidification of matter, and also "rigid" bodies. The "point of departure" which he suggests is that " the true and proper basis of statics is to be sought for in the principle of linear and angular momentum. Regarding statics as the doctrine of the equivalence of forces, I would define the word 'equivalent,' and say that two sets of forces are 'equivalent' when, and only when, they produce the same effect on the linear and on the angular momentum of any material system to which they may be applied : i.e. when they produce the same rate of change of momentum in any assigned direction, and the same rate of change of moment of momentum about any assigned axis." $\mathrm{He}$ believes that on examination the objections arising from the supposed difficulty and abstruseness of this mode of treatment, "will disappear, and that on the whole the method will be found to be really much simpler than that at present in vogue. The main difficulty is at the outset."

A brief but interesting discussion followed, enlivened as it was by a friendly passage of arms over the term force of inertia.

R. T.

\section{THE CHEMISTRY OF THE PLANTÉ AND FAURE ACCUMULATORS \\ PART V. \\ I. Infuence of Strength of Acid}

$\mathrm{N}$ the second part of this communication in NATURE, vol. xxv. p. $46 \mathrm{I}$, when treating of the charging of the cell, we pointed out that in the electrolysis of dilute sulphuric acid between lead electrodes, two totally different reactions might be obtained. The positive metal becomes thinly coated with lead sulphate when the current employed is of small density, but with lead peroxide when the density of the current is of greater magnitude. This latter action is, of course, what takes place in the ordinary formation of a Planté battery. The chemical change, therefore, which goes on at the positive electrode is to a certain extent dependent wpon the strength of the current.
It appeared also of both theoretical and practical interest to determine whether the chemical change was also influenced by the strength of the acid employed. Our experiments consisted in passing a current of uniform strength, about I ampere, between electrodes of lead, I2 square inches in size, in varying strengths of sulphuric acid, and estimating in each case the amount of oxygen fixed by the positive electrode. We determined this for successive five minutes of time, and as such actions are not always very uniform, we made in each instance more than one experiment. The results are given in the following table :-

\begin{tabular}{|c|c|c|c|c|c|c|}
\hline \multirow{2}{*}{$\begin{array}{l}\text { Strength } \\
\text { of acid. }\end{array}$} & \multirow{2}{*}{ Expt. } & \multicolumn{5}{|c|}{ Percentage of oxygen fixed. } \\
\hline & & $\begin{array}{c}\text { First } \\
5 \text { mins. }\end{array}$ & $\begin{array}{l}\text { Second } \\
5 \text { mins. }\end{array}$ & $\begin{array}{c}\text { Third } \\
5 \text { mins. }\end{array}$ & $\begin{array}{l}\text { Fourth } \\
5 \text { mins. }\end{array}$ & Total. \\
\hline I to 5 & $\begin{array}{l}\text { I. } \\
\text { II. }\end{array}$ & $\begin{array}{l}38 \cdot 1 \\
39 \cdot 5\end{array}$ & $\begin{array}{l}28 \cdot 6 \\
30^{\circ} 2\end{array}$ & $\begin{array}{l}28 \cdot 6 \\
25 \cdot 6\end{array}$ & $\begin{array}{l}33 \cdot 3 \\
30 \cdot 2\end{array}$ & $\begin{array}{l}128.6 \\
\text { I } 25.5\end{array}$ \\
\hline I to 10 & $\begin{array}{l}\text { I. } \\
\text { II. }\end{array}$ & $\begin{array}{l}43 \cdot 4 \\
44^{\circ} \cdot 1\end{array}$ & $\begin{array}{l}3^{8 \cdot 7} \\
39 \cdot 3\end{array}$ & $\begin{array}{l}29 \cdot 2 \\
29 \cdot 3\end{array}$ & $\begin{array}{l}34 \\
34.9\end{array}$ & $\begin{array}{l}145.3 \\
147.6\end{array}$ \\
\hline I to 50 & $\begin{array}{l}\text { I. } \\
\text { II. } \\
\text { III. }\end{array}$ & $\begin{array}{l}48 \cdot 3 \\
46 \cdot 2 \\
54\end{array}$ & $\begin{array}{l}39^{\circ} 6 \\
43^{\circ} 9 \\
4^{\circ}\end{array}$ & $\begin{array}{l}35 \cdot 3 \\
23 \\
35 \cdot 3\end{array}$ & $\begin{array}{l}22.4 \\
30 \\
35.5\end{array}$ & $\begin{array}{l}145^{\circ} 6 \\
143 \\
165\end{array}$ \\
\hline I to 100 & $\begin{array}{r}\text { I. } \\
\text { II. } \\
\text { III. }\end{array}$ & $\begin{array}{l}42 \\
42 \cdot 4 \\
5 \mathrm{I} \cdot \mathrm{I}\end{array}$ & $\begin{array}{l}38 \cdot 3 \\
40 \\
44^{\circ} \cdot 2\end{array}$ & $\begin{array}{l}33.9 \\
37.8 \\
34.9\end{array}$ & $\begin{array}{l}29.5 \\
35.5 \\
34^{\circ} 9\end{array}$ & $\begin{array}{l}1437 \\
155.7 \\
165.1\end{array}$ \\
\hline I to 500 & $\begin{array}{l}\text { I. } \\
\text { II. }\end{array}$ & $\begin{array}{l}46 \cdot 6 \\
46 \cdot 4\end{array}$ & $\begin{array}{l}32 \cdot 6 \\
27\end{array}$ & $\begin{array}{l}27 \\
27\end{array}$ & $\begin{array}{l}27 \\
18\end{array}$ & $\begin{array}{l}1326 \\
118.4\end{array}$ \\
\hline I to 1000 & $\begin{array}{l}\text { I. } \\
\text { II. }\end{array}$ & $\begin{array}{l}90 \cdot 6 \\
90 \cdot 8\end{array}$ & $\begin{array}{l}8 \mathrm{I} \cdot \mathrm{I} \\
77\end{array}$ & $\begin{array}{l}76 \cdot 4 \\
72 \cdot 3\end{array}$ & $\begin{array}{l}57 \cdot 5 \\
63 \cdot 1\end{array}$ & $\begin{array}{l}305^{\circ} 6 \\
303^{\circ} 2\end{array}$ \\
\hline
\end{tabular}

It appears from this that the strong sulphuric acid (1 to 5) is not quite so favourable to the action as the more dilute ( $\mathrm{I}$ to $\mathrm{IO}$ ), but that between this latter proportion and $I$ to 500 there is no great difference in the amount of oxygen fixed, and therefore of corrosion of the plate. The appearance of the plate in every instance indicated the formation of only lead peroxide. With sulphuric acid diluted with rooo parts of water, the amount of oxygen fixed, and therefore of corrosion, was at least doubled, while the chemical action was very different. On parts of the electrode, streaks of a mixture apparently of the yellow and puce-coloured oxides were seen. On other parts a white substance formed and was easily detached, falling in clouds into the liquid. Where this latter action took place, the plate was visibly the most corroded. This white substance gave on analysis $\mathrm{SO}_{4}$ equivalent to 73.6 per cent. of lead sulphate, suggesting the idea that it was a basic sulphate of the composition $2 \mathrm{PbSO}_{4}, \mathrm{PbO}$, which would require $73^{\prime} 1$ per cent. As the peroxidation of the lead is required, and the corrosion of the plate is to be avoided as much as possible, it is evident that this extremely dilute acid must be avoided. It has already been shown that if the sulphuric acid is entirely removed from solution, as sometimes happens in an accumulator, the lead is simply converted into the hydrated protoxide, and therefore corroded without any good effect.

2. Function of Hydrogen.-In the formation of a secondary cell, after the complete reduction of oxide or sulphate to metallic lead, bubbles of hydrogen gas are seen to escape from the lead plate. It has been assumed that a portion of this is occluded by the lead, or in some other way enters into association with it, and it has been 